\title{
Assessing motivation and learning strategy usage by dually enrolled students
}

\author{
Molly C. Day ${ }^{1 *}\left(\mathbb{D}\right.$, Heather M. Kelley ${ }^{2}$, Blaine L. Browne ${ }^{2}$ and Steven J. Kohn²
}

\author{
* Correspondence: mollydayrrt@ \\ yahoo.com \\ ${ }^{1}$ Department of Psychology, \\ Counseling, and Family Therapy, \\ Valdosta State University, 1802 Lake \\ Circle Dr. Bainbridge, Valdosta, GA \\ 39819, USA \\ Full list of author information is \\ available at the end of the article
}

\begin{abstract}
Theoretical frameworks grounded in the social cognitive theory are used to discuss the need for assessing motivation, self-efficacy for learning and performance, metacognitive self-regulation of dually enrolled students. This study assessed motivation and learning strategy usage by Dually Enrolled Students participating in Georgia's Dual Enrollment program. The research was conducted on 213 high school aged 14 to 18 years, in grades 9-12, and attended a high school in a seven-county service area in southwest Georgia. Participants all were taking classes under a program that allows them to simultaneously earn high school and college credit, and required them to attend a high school and college concurrently either at a technical college of the Technical System of Georgia, or a state college of the University System of Georgia. The research questions were answered using a crosssectional survey, the Motivated Strategies for Learning Questionnaire, and demographics were used to classify participants based on age, grade, gender, number of classes completed in the Dual Enrollment program, teacher type for instruction, and the format/location of college class taken. The study's findings added to the existing knowledge base regarding teenage students who are expected to conform to the role of college student simply because they were deemed academically equipped to take college classes. Furthermore, the findings of this study suggest the importance of implementing additional acceptance requirements to make sure students possess the maturity, motivation, and learning strategy application knowledge to be successful in college classes and that faculty has been trained to accommodate the learning needs of this specific type of learner.

Keywords: Dual enrollment, College readiness, Achievement goal theory, Expectancy-value theory, Self-efficacy, Self-regulation, MSLQ
\end{abstract}

The existing body of literature pertaining to exploration of Dual Enrollment students' perceptions of academic outcomes and motivation is growing, yet very little literature specifically addresses the motivational orientations and learning strategies used while participating in the Dual Enrollment program. A program of this type changes the dynamics of college for both the student participant and the faculty teaching the classes. The Rennie Center for Educational Research and Policy advocates inadequate academic preparation and lack of an intimate support system of guidance as leading factors of college dropout among high school students so in response to the changing

(c) The Author(s). 2020 Open Access This article is licensed under a Creative Commons Attribution 4.0 International License, which permits use, sharing, adaptation, distribution and reproduction in any medium or format, as long as you give appropriate credit to the original author(s) and the source, provide a link to the Creative Commons licence, and indicate if changes were made. The images or other third party material in this article are included in the article's Creative Commons licence, unless indicated otherwise in a credit line to the material. If material is not included in the article's Creative Commons licence and your intended use is not permitted by statutory regulation or exceeds the permitted use, you will need to obtain permission directly from the copyright holder. To view a copy of this licence, visit http://creativecommons.org/licenses/by/4.0/. 
demands of society and the need for a more efficient education system to better prepare students, the Gates Foundation supported Dual Enrollment as an early-college effort (Deruy, 2015). Currently, it is assumed that students who can pass the entrance tests be deemed "college ready" and are thrown into the role of college student though they may lack the nonacademic skills to be successful in college. Students put in the "sink or swim" position by Dual Enrollment reiterates that the program should not be considered an experimental college experience because the consequences of doing poorly will be reflected on the student's college transcript permanently.

Literature states that the goal of a comprehensive college programs is to assist students with cognitive strategies, content knowledge, self-management skills, and knowledge about post-secondary education (Morrow \& Torrez, 2012) yet the Dual Enrollment program expects students to already possess these characteristics. In fact, few students naturally possess the skills to independently plan, monitor, and assess their learning (Zumbrunn, Tadlock, \& Roberts, 2011) which is why expedited learning programs must give students the self-management skills necessary be successful in college courses. The purpose of this study was to explore motivation and learning strategy usage by students who just started taking college courses in the DE program and comparing those to students who have completed more classes in the program to determine if taking college classes advances motivational orientations and more advanced learning strategy usage as students obtain more college credits.

Based on admission standards, high school students are expected to thrive in the college environment based simply on satisfactory entrance test scores however; academic success in college requires pre-existing capabilities that these students may not have yet developed (Kitsantas, Winsler, \& Huie, 2008). Potentially, early exposure to college courses allow students to develop necessary skills and coping strategies which will lead to greater persistence and completion rates (Kanny, 2015) but research confirmations academically prepared high school students can still struggle with nonacademic concepts, specifically the increased rigor, greater expectations, and norms of transitioning into the role of college student at a young age. Karp (2007) states students who fail to persist in postsecondary education is due to a lack of understanding of the normative demands placed on college students and their inability to successfully meet the demands set forth.

Literature supports disparities in rigor and structure compared to traditional college classes. Until 2008, very little research was done to study the pedagogy and teaching that was occurring in the Dual Enrollment classroom. Hughes and Edwards (2012) found that considerable differences were occurring based on location (high school or college campus) and teacher type (college faculty or high school teacher) in Dual Enrollment courses. The growth of the accelerated learning program indicates a need to ascertain the program's overall effectiveness for meeting the learning needs of Dual Enrollment students and to look for instructional program improvements that would benefit these specific types of learners. According to the Governor's Office of Student Achievement (2017), students who participate in Dual Enrollment are likely to graduate from high school within 4 years and are more likely to enroll in postsecondary coursework and complete a postsecondary credential relative to other high school graduates. However, research that is more rigorous is needed to determine whether the differences are more the result of participating in Dual Enrollment or a reflection of the individual 
students' characteristics of the students who dually enroll (Rauschenberg \& Chalasani, 2017). The findings of the study revealed high school teachers were challenged with what "college-level" was, appropriate rigor level of courses, and how to create a college environment (Hughes \& Edwards, 2012, p.30). Though the focus of the study was on instructor issues, the results indicated students who struggled academically and failed to persist in the DE program (Hughes \& Edwards, 2012). Many college officials have expressed concern that the rigor in a high school teacher's classroom and that of a college faculty member differ and that by using high school teachers in place of college faculty, students will overestimate their abilities which could lead to them struggling in college. The importance of instructor training became obvious if faculty was to improve instructional practices, generate lessons on pedagogical strategies and lead to better student outcomes (Hughes \& Edwards, 2012).

\section{Purpose of study}

The growth of the accelerated learning program indicates a need to ascertain the program's overall effectiveness for meeting the learning needs of Dual Enrollment students and to look for instructional program improvements that would benefit these specific types of learners. National Dual Enrollment data shows that Dual Enrollment students in some states do substantially better in college than others and there are large achievement gaps between different income groups in various states. The Community College Research Center (2017), found that college graduation rates for Dual Enrollment students vary widely by state and income level of student and that further research should be done to find out why some students in certain states do substantially better in college and why there are large achievement gaps between different income groups of students. A few studies have concluded that Dual Enrollment improves student achievements and success, but none have included the how aspect of why this phenomenon is occurring. Further, there is a lack of research that addresses whether students' motivation and application of learning strategies progresses as they gain more experience as a college student. Lastly, there is a lack of research on teacher impact for the development of motivation and use of learning strategies. The lack of research available highlights the need for further research on Dual Enrollment students' perceptions of their motivation, learning styles utilized, and their instructor's role in those concepts. This information will provide educators with a better understanding of how Dual Enrollment classes are preparing students for the college experience, but also will determine if instructional methods should be altered to increase student motivation and develop more advanced learning strategies.

The goal of the study was to measure Dual Enrollment students' motivational, cognitive and metacognitive (self-regulation) characteristics while participating in college classes. More specifically, this study compared the motivation and learning strategies of new students to those students who had taken additional classes to determine if there is a correlation between number of classes taken and reported motivation and learning strategies being used. Further, the study also examined the impact of the instructor type (e.g., a high school teacher hired as an adjunct college faculty or full-time college faculty) on motivation and learning strategies used by Dual Enrollment students. Lastly, this study assessed motivation and learning strategy usage based on class location (college campus, high school campus, online, or a combination of the locations). Since self- 
efficacy and self-regulation of the learner can predict how well students will succeed in an academic pursuit, the information can inform program policy makers and school administrators on program effectiveness and overall success of the program while still improving Dual Enrollment practices (Magno, 2011). Learning more about the relationship between motivation and learning strategies used by Dual Enrollment participants, could help instructors and school officials lead to better planned programs, smoother college transition, and a more authentic college experience. The following research questions guided this study:

(1) What are student perceptions of motivational, cognitive and metacognitive (self regulation) characteristics while enrolled in the Dual Enrollment program?

(2) What is the relationship between number of classes taken in the Dual Enrollment program and students' perceptions of motivation and learning strategies?

(3) What is the difference in the motivation and learning strategies of Dual Enrollment students taught by high school teachers and those taught by full time college faculty?

(4) What is the difference in reported MSLQ scores for students based on class location?

\section{Conceptual framework}

To enhance understanding of the relationship between motivational, cognitive and metacognitive (self- regulation) characteristics, the authors considered extant research on: (1) social cognitive theory and academic self-efficacy, (2) self-regulation theory and SRL, (3) achievement goal and expectancy value theory, (4) comparison of teacher types and (5) comparison of class location.

\section{Social cognitive theory and academic self-efficacy}

Grounded in the self-efficacy theory, academic self-efficacy is a multidimensional construct which is situational in nature so differentiation of academic situations produces different results of self-reported academic self-efficacy. Motivation and personal accomplishment are the basis of self-efficacy; meaning that if learners do not believe their actions will produce a desired result, they will fail to act, especially in the face of difficulties (Pajares, 2002). Bandura (1997) asserts "people's level of motivation, affective states, and actions are based more on what they believe than on what is objectively true" (p. 2). Humans have the capacity to influence their actions and produce certain results through thought processes, motivation, affect, and action as mechanisms of personal agency (Bandura, 1997). Making judgements about capabilities, anticipating probable effects, and regulation of behavior are all part of a belief system model which is vital for survival and progress (Bandura, 1999). Students' academic behaviors are predicted by their capability beliefs more than what they are capable of actually accomplishing which means that self-efficacy levels determine what students do with the knowledge and skills they possess (Pajares, 2002). In the classroom, academic selfefficacy affects learner's perceptions which will effect task outcomes (McGrew, 2008). Perceived performances by the individual is a strong influencer of academic accomplishment or failure (Eccles, 2005). 
Self-efficacy beliefs influence the choices and courses of action that students choose to take, effort exertion, perseverance and resilience when challenges arise; the higher the student's self-efficacy, the higher the effort, persistence, and resilience (Pajares, 2002). Self-efficacy explains why students will only participate in activities where they believe they are competent and confident in their actions so that that their actions will have the desired consequences. In an academic setting, researchers found self-efficacy and achievement motivation to be the strongest effects on college GPA (Duncan \& McKeachie, 2005).

\section{Self-regulation theory and SRL}

The self-regulation theory is derived from Bandura's social cognitive theory (1986) and provides a theoretical basis for the development of a model of self-regulated learning (SRL) where the triadic personal, behavioral, and environmental factors interact to give students an opportunity to control their learning in a self-directed approach (Bandura, 1986; Zimmerman, 2000). Academic self-regulation is a self-directive process where students transform mental abilities into academic skills (Zimmerman, 1989). According to Wolters (1998), effective learning is goal oriented so in order to achieve the goals set forth, learners must modify or adapt their strategies to fit situational demands. Based on this idea, students must premeditate goals, and must observe, judge, and be able to react to their perceptions of goal processes actively during the learning process (Schunk \& Zimmerman, 1994). Zimmerman (2002) states that self-regulation of learning involves more than detailed knowledge of a skill; it involves the self2-awareness, selfmotivation, and behavioral skill to implement that knowledge appropriately (p. 66).

Learners selectively use various learning strategies to improve their ability to learn (Kivinen, 2003). SRL as a goal-oriented process that emphasizes constructive monitoring, regulating, and controlling one's learning includes cognitive, motivational, emotional, and social factors (Puustinen \& Pulkkinen, 2001). Students are responsible for setting goals, strategies to obtain those goals, and to structure learning environments so that learning will be conducive to reaching those goals. Theorist of self-regulation view learning as a cyclical, multidimensional process, which continually blends personal, behavioral, and conceptual components based on feedback from prior performance (Zimmerman, 1986). Since the factors are continually changing, adjustments by the learner must be constantly corrected (Zimmerman, 2000). Self-regulation increases flexibility and adaptability so that individuals can adapt and allows meet societal and situational demands (Kaur \& Kaur, 2014). To master academic skills, learners must behaviorally apply cognitive strategies to a task that is within a contextually relevant setting (Kivinen, 2003). Self-regulated learning is the connection between motivation and cognition (Pintrich, 1989).

\section{Achievement goal and expectancy value theories}

Faculty play a part in the development of students' motivational, cognitive, and metacognitive characteristics. Motivation and cognition influence study behaviors and performance (Crede \& Phillips, 2011) while learning motivation and achievement goals influence learner behavior and performance in the classroom settings (Ali, Hatala, Gašević, \& Winne, 2014). The achievement goal theory, included in the value 
component, are the reasons students engage in academic tasks. Based on the achievement goal theory, students' experiences are linked to the goals students pursue for their course or academic task (Senko, 2016). Mastery goals and performance goals represent varying reasons for engaging in a task as well as different evaluations of success, as well. Mastery goals reflect a desire to develop competence by improving or learning as much as one can and success is based on self-referential standards or task-based standards (Senko, 2016).

Normative standards define success for performance goals, which are focused on demonstrating competence by outperforming peers (Senko, 2016). Therefore, based on the achievement goal theory, mastery goals stimulate learners to seek challenges, increase effort, and facilitate learning (Senko, 2016). Students participating in the Dual Enrollment program are motivated by the desire to develop their competence and maximize their potential or to demonstrate their competence and prove something to themselves (Senko, 2016). According to the expectancy value theory, individuals' expectancies for success are directly tied to the value they have for success affect their motivation to perform different achievement tasks (Wigfield, 1994).

\section{Comparing high school teachers and college faculty teaching dual enrollment}

Critics of the program find that neither high school teachers nor college professors are entirely equipped to teach for classes for Dual Enrollment. College professors are critiqued for having no pedagogical training to teach younger students (Hughes \& Edwards, 2012) yet the common practice of hiring high school teachers as adjunct instructors has created issues with rigor and transferability of courses (Jenkins, 2017). In order for high school teachers to teach for a college, they must obtain additional credentials to be deemed as eligible. Conversely, college faculty with no pedagogical or specific teacher training may struggle with classroom management, discipline, or effective teaching practices for high school students. While the opportunity to teach younger students can inspire professional development of both high school teachers and college faculty, previous studies suggest college faculty may be uninterested altogether in teaching high school students (Tobolowsky \& Allen, 2016). Dually enrolled students reported in previous college classes taken, faculty "explicitly expressed their disdain for having high school students in their courses" (Kanny, 2015, p. 66). The study further revealed negative interactions with faculty members and discussed faculty's concerns for even the most highly motivated and dedicated students in regards to their maturity (Tobolowsky \& Allen, 2016). To ensure the best chance of success for students in the program, Hughes (2010) suggests program administrators identify instructors who are motivated to participate in extra training and experienced in teaching younger students.

College faculty emphasize key thinking skills to promote deeper level thinking. Faculty states course goals for students as the ability to make inferences, interpretation of results, analyze conflicting explanations and solve complex problems (National Research Council, 2002). In general, college faculty expect deeper levels of thinking from students. Comparison between college instructors and high school teachers reveal that college faculty pace their courses more rapidly, emphasize different material aspects of course content, and set different goals that high school instructors (Conley, 2006). The 
expectations of most faculty are the source of many issues within the Dual Enrollment classroom. Less experienced learners are usually deficient in many critical skills anticipated by faculty. This problem forces faculty to be able to recognize the needs of a younger learner and to shift teaching practices, alter conventional classroom management, and increase pedagogical content knowledge if they want to transition young learners to successful college students.

\section{Class locations}

Convenience and higher enrollment numbers are usually the reason for the high school campus being selected as the location but by offering classes in an environment where the student is comfortable, another advantage also emerges. Khan (2013) noted students will be more comfortable, have higher self-efficacy, and be more willing to ask for help from the teacher when the student in on a high school campus. By offering classes on high school campuses, colleges can increase course access for more students (Tobolowsky \& Allen, 2016). Burns and Lewis (2000) study revealed there is a symbiotic relationship between high schools the colleges who participate in the Dual Enrollment however, students who attended classes on a high school campus were less satisfied than those who took courses on a college campus which implies the course location affects the climate of Dual Enrollment students. Further, the students also believed that by taking courses on a college campus, it cultivated them to be more independent, responsible, and were of "greater value" (Burns \& Lewis, 2000, p. 3). Lastly, students who enrolled in classes on a college campus were more likely to continue college classes than those on a high school campus because they believed their experience was more authentic (Burns \& Lewis, 2000). Classroom observations revealed disparities in rigor and structure compared to traditional college classes. The best classes observed, were high-quality, pedagogically sound, and equivalent to what was offered on a college campus (Karp, 2012).

\section{Method}

\section{Participants}

The participants for this study were drawn from a convenience sample, limited to selected high school students and home-schooled students who participated in the Dual Enrollment program in Southwest Georgia in the Fall of 2018. The study included purposefully selected participants at two different institutions: target institutions and surrounding high schools. All students participating in the program at two institutions in Southwest Georgia were considered as the population. This provided an overall sample size of 213 students consenting to participate and answer the Motivated Strategies Learning Questionnaire (MSLQ). Based on literature by Karp (2012), higher selfefficacy and self-regulation skills develop over time therefore, the questionnaire was administered after midterm of the Fall 2018 semester. This gives dually enrolled students who have not completed any college courses the opportunity to participate as well as students who have taken multiple college courses. The survey resulted in 213 participants with $67.6 \%$ being female and $31 \%$ being male. Six percent of participants student were 14 years old, $11.1 \%$ were 15 years old, $26.4 \%$ were 16 years old, $34.3 \%$ were 17 years old, $18.5 \%$ were 18 years old, and $3.7 \%$ were 19 years old. Survey participants were 
ranged in grades 9th-12th; high school seniors 50\%, 22.7\% were juniors, $19 \%$ sophomores, and $8.3 \%$ freshmen. The ethnicity of the participant population was diverse, with 57.3\% White, 24.6\% Black, 0.8\% Cuban, 2.6\% Asian, 0.4\% Brown, 8\% Hispanic, 2.2\% Mixed, 3.1\% Other.

\section{Materials}

A demographic questionnaire consisting of 23 questions addressed student's age, ethnicity, grade, high school and college currently being attended, number of days per week classes are attended, confidence level of student, expected total number of credit hours to be completed in the DE program, teacher classification for previous and current $\mathrm{DE}$ classes, location of previous and current DE classes, number of credit hours previously and currently taking in the DE program, subject of previous and current classes taken, expected final letter grade for the semester, post-graduation plans, and extracurricular or work obligations.

\section{Description of instrument}

The main research instrument used will be the MSLQ, a self-reporting Likert-type scale, to measure the student's cognitive and metacognitive strategies as well as their motivation and specific techniques (Erickson \& Noonan, 2013). accompanied by a demographic questionnaire created by the researcher to obtain participants' background information relevant to their involvement in this study (i.e., age, grade, school, amount of credit hours taken, current class enrollment, expected grade, etc.). Students completed both scales, during a single administration, in counterbalanced order. The MSLQ is an 81-item, self-report instrument designed to measure college students' motivational orientations and their use of various learning strategies (Pintrich, Smith, Duncan, \& McKeachie, 1991). The conceptualizations of learning strategies were based on cognitive and social cognitive approaches of teaching and learning (Pintrich et al,, 1991). The motivation section of the instrument has 31 items about the motivational beliefs and the learning strategies section consists of 31 items about students use of different cognitive and metacognitive strategies. For the current study, three motivational components of MSLQ (value, expectancy and affect) were used to measure the motivational beliefs of the students. The value component included the constructs intrinsic goal orientation, extrinsic goal orientation, and task value while the expectancy component included the constructs control of learning beliefs and self-efficacy for learning and performance and the affective component test anxiety. As a self-report instrument, the MSLQ had limitations, with the main questions surrounding the reliability and validity. "Traditional measures of the stability aspect of reliability are difficult to use for instruments that are intended to tap into constructs that are context dependent" (Duncan \& McKeachie, 2005, p. 124). The reliability of the MLSQ questionnaire in this study was very similar to that found in the original 1990 study, with 380 students of various subjects in Midwestern College (Pintrich et al., 1991).

Social desirability bias was considered a significant threat to the construct validity of all self-report instruments. However, despite limitations of the MSLQ, the instrument was and is considered a practical method for assessing students' motivation and use of self-regulated learning strategies. Hundreds of researchers have used the MSLQ in 
numerous countries around the world. The overall internal consistency reliability and Cronbach alphas provided by Pintrich et al. (1991) have been adequate (.78 and .71 for motivational scales and learning strategies). Cronbach alphas from this study were adequate. Extensive psychometric development of the MSLQ by other researchers showed similar internal consistency reliability estimates for the MSLQ with independent samples.

\section{Procedure}

The implementation of this study began with the students first completing the demographic questionnaire. All students then answered the MSLQ questionnaires online, using an anonymous link provided by the researcher. Prior to participation in the study consent was obtained from all students, parents (if the student was under the age of 18), superintendents, college presidents, Dual Enrollment coordinators, and guidance counselors.

\section{Results}

Research question one examined students' perceived skills while participating in the Dual Enrollment program. The initial research question determined the MSLQ scores of high school students participating in the Dual Enrollment program. Descriptive statistics and various correlations described the data based on participant's demographic information: gender, ethnicity, grade, age, number of classes completed in the DE program, where those classes were taken, who taught those classes, how many days per week the college classes met, extracurricular participation and other influencers of the Dual Enrollment program (Table 1).

One-way Analysis of Variances (ANOVA) were ran using the MSLQ Subscales as the Dependent variables. These ANOVAs were used to compare the means of the various demographic variables. For each ANOVA, the test of homogeneity of variances was assessed to ensure the variances within each group were similar. The results supported the hypotheses students MSLQ scores differed based on various demographics. The findings indicated a negative correlation with extracurricular activities participation. One hundred thirty-three (62.74\%) of study participants indicated they currently were involved in extracurricular activities or have a job besides participating in college classes offered through the Dual Enrollment program.

One hundred twelve out of the 133 students participating in extracurricular activities spend less than $15 \mathrm{~h}$ weekly doing extracurricular activities. A Pearson's correlation coefficient was computed to assess the relationship between the participation in extracurricular activities and all MSLQ subscales. Students who did not participate in extracurricular activities were assigned a dummy variable of 0 and participating students were assigned a 1. A negative weak correlation was found between the extrinsic goal orientation subscale $[\mathrm{r}(194)=-.142, n=196, p=.046]$, the task value subscale $[\mathrm{r}(182)=-.211, n=184, p=.004]$ and help seeking subscale and extracurricular participation $[\mathrm{r}(184)=-.190, n=186, p=.009]$ with extracurricular participation. A positive weak correlation was found between extracurricular participation and test anxiety [ $\mathrm{r}$ $(191)=.163, n=193, p=.024$ ]. Students who participated weekly in extracurricular activities scored lower on the extrinsic goal orientation subscale and expected a lower 
Table 1 Demographic participant information

\begin{tabular}{|c|c|c|c|}
\hline Variable & Levels & Number of subjects & Percentage of subjects \\
\hline \multirow[t]{2}{*}{ Gender } & Male & 67 & $31 \%$ \\
\hline & Female & 146 & $67.6 \%$ \\
\hline \multirow[t]{9}{*}{ Ethnicity } & White/Caucasian & 128 & $57.3 \%$ \\
\hline & Black/African & 54 & $24.6 \%$ \\
\hline & American & 2 & $0.8 \%$ \\
\hline & Cuban & 6 & $2.6 \%$ \\
\hline & Asian & 1 & $0.4 \%$ \\
\hline & Brown & 18 & $8 \%$ \\
\hline & Hispanic & 5 & $2.2 \%$ \\
\hline & Mixed & 1 & $0.4 \%$ \\
\hline & Other & 7 & $3.1 \%$ \\
\hline \multirow[t]{6}{*}{ Age } & 14 & 13 & $6 \%$ \\
\hline & 15 & 24 & $11.1 \%$ \\
\hline & 16 & 57 & $26.4 \%$ \\
\hline & 17 & 74 & $34.3 \%$ \\
\hline & 18 & 40 & $18.5 \%$ \\
\hline & 19 & 8 & $3.7 \%$ \\
\hline \multirow[t]{4}{*}{ Grade } & 9 & 18 & $8.3 \%$ \\
\hline & 10 & 41 & $19 \%$ \\
\hline & 11 & 49 & $22.7 \%$ \\
\hline & 12 & 108 & $50 \%$ \\
\hline \multirow[t]{6}{*}{ High school } & HS A & 47 & $21.8 \%$ \\
\hline & HS B & 36 & $16.7 \%$ \\
\hline & HS C & 44 & $20.4 \%$ \\
\hline & HS D & 41 & $19.0 \%$ \\
\hline & Other & 44 & $20.4 \%$ \\
\hline & Homeschooled & 4 & $1.9 \%$ \\
\hline \multirow[t]{2}{*}{ College } & Technical College & 110 & $50.9 \%$ \\
\hline & State University & 106 & $49.1 \%$ \\
\hline \multirow[t]{7}{*}{ Current class location } & High School Campus & 10 & $9.8 \%$ \\
\hline & College Campus & 13 & $12.7 \%$ \\
\hline & Online & 23 & $22.6 \%$ \\
\hline & Both HS \& CC & 9 & $8.8 \%$ \\
\hline & HS \& Online & 13 & $12.7 \%$ \\
\hline & CC \& Online & 21 & $20.6 \%$ \\
\hline & HS, CC \& Online & 13 & $12.8 \%$ \\
\hline \multirow[t]{4}{*}{ Teacher type } & High School Teacher & 34 & $15.8 \%$ \\
\hline & College Faculty & 144 & $67.0 \%$ \\
\hline & Other-Both HS \& CF & 29 & $13.5 \%$ \\
\hline & Missing & 8 & $3.7 \%$ \\
\hline
\end{tabular}

final letter grade. There were significant differences in subscale scores based on age for the control, self-efficacy for learning and performance, metacognitive self-regulation, and help seeking subscales (Fig. 1). 


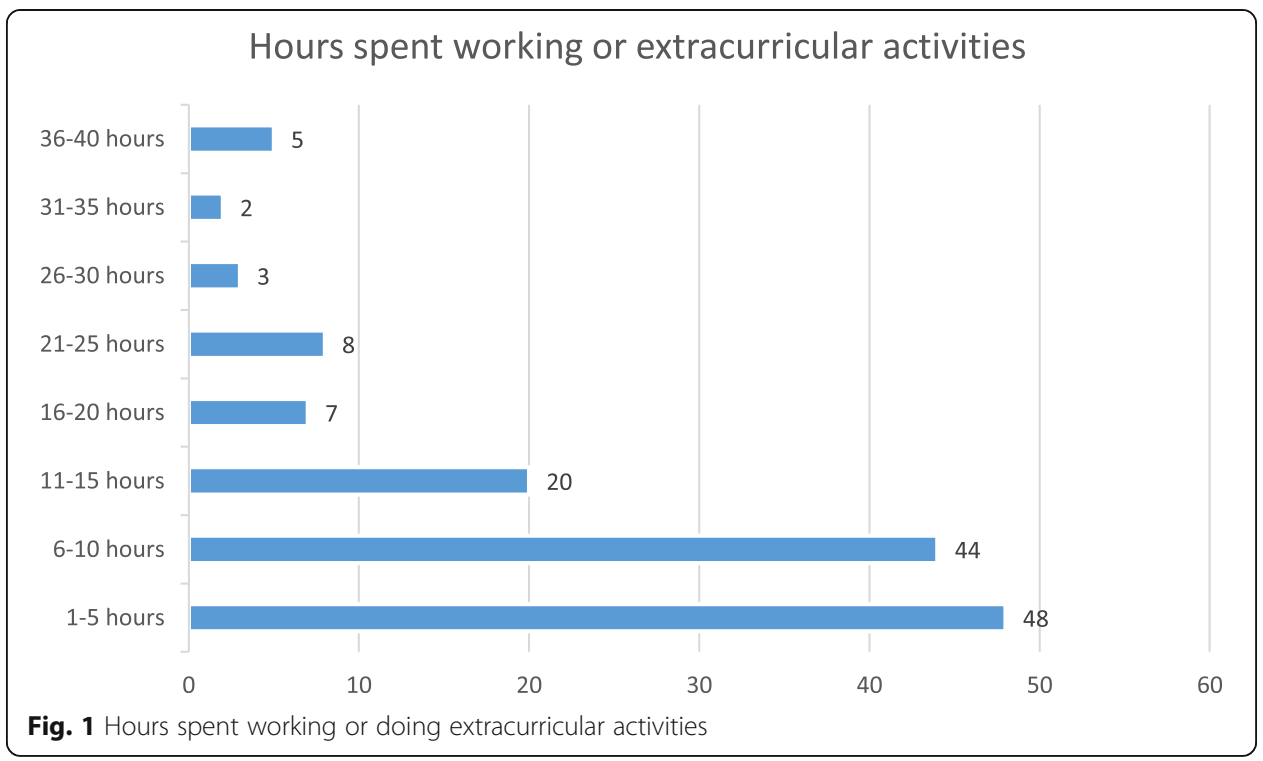

Students who attended college classes 5 days per week scored the lowest on all MSLQ subscales but scored highest for test anxiety and rehearsal subscales. An ANOVA was conducted to compare the effect of number of days weekly the student attended college classes on MSLQ Subscale Scores (0 days, 1 day, 2 days, 3 days, 4 days, 5 days). There was a significant effect at the $p<.05$ for the number of days per week on the control ( $\mathrm{F}$ $(5,90)=1.77, p=.028, \eta 2 p=.045)$, elaboration $(\mathrm{F}(5,83)=1.59, p=.031, \eta 2 \mathrm{p}=.033)$, and rehearsal subscales $(\mathrm{F}(5,84)=1.75, \mathrm{p}=.045, \eta 2 \mathrm{p}=.068)$. Post hoc comparisons using the Tukey HSD test indicated that the mean score on the control subscale of students attending class online $(\mathrm{M}=4.88, \mathrm{SD}=.89)$ and students attending class 4 days per week $(\mathrm{M}=5.54, \mathrm{SD}=.85)$ was significantly different at the $p=.002$ level. No other significant post hoc comparisons were found. Tukey HSD test also indicated a significant difference in the elaboration subscale for students who attended classes 4 days per week $(\mathrm{M}=4.44, \mathrm{SD}=1.44)$ and students who attended classes 5 days per week $(\mathrm{M}=4.20$, $\mathrm{SD}=1.22), p=.021$. Post hoc tests also showed there was also a significant difference in means of students on the rehearsal subscale for students who took classes 4 days per week $(\mathrm{M}=4.60, \mathrm{SD}=1.97)$ and those who took classes online $(\mathrm{M}=4.47, \mathrm{SD}=1.20$, $p<.001), 2$ days per week $(\mathrm{M}=4.43, \mathrm{SD}=1.25, p=.008)$, and 5 days per week $(\mathrm{M}=$ $3.91, \mathrm{SD}=1.27, p<.001)$. Grade levels showed significant differences in control of learning and rehearsal subscales. Gender findings revealed females scored significantly higher on rehearsal and elaboration subscales than males did. A point-biserial correlation was computed to assess the relationship between gender and all MSLQ subscales. Dummy codes were used and showed weak positive correlations for the Elaboration subscale $[\mathrm{rpb}=.197, n=180, p=.008]$ and $[\mathrm{rpb}=.171, n=180, p=.020]$ for the Rehearsal subscale.

Students were asked what class(es) were most difficult for them. The following table shows that students perceived Science, Math, English, and History as the most difficult courses (Fig. 2).

Students who expected to get a final letter grade of an "A", scored significantly higher on the extrinsic goals orientation, time and study environment, and help seeking 


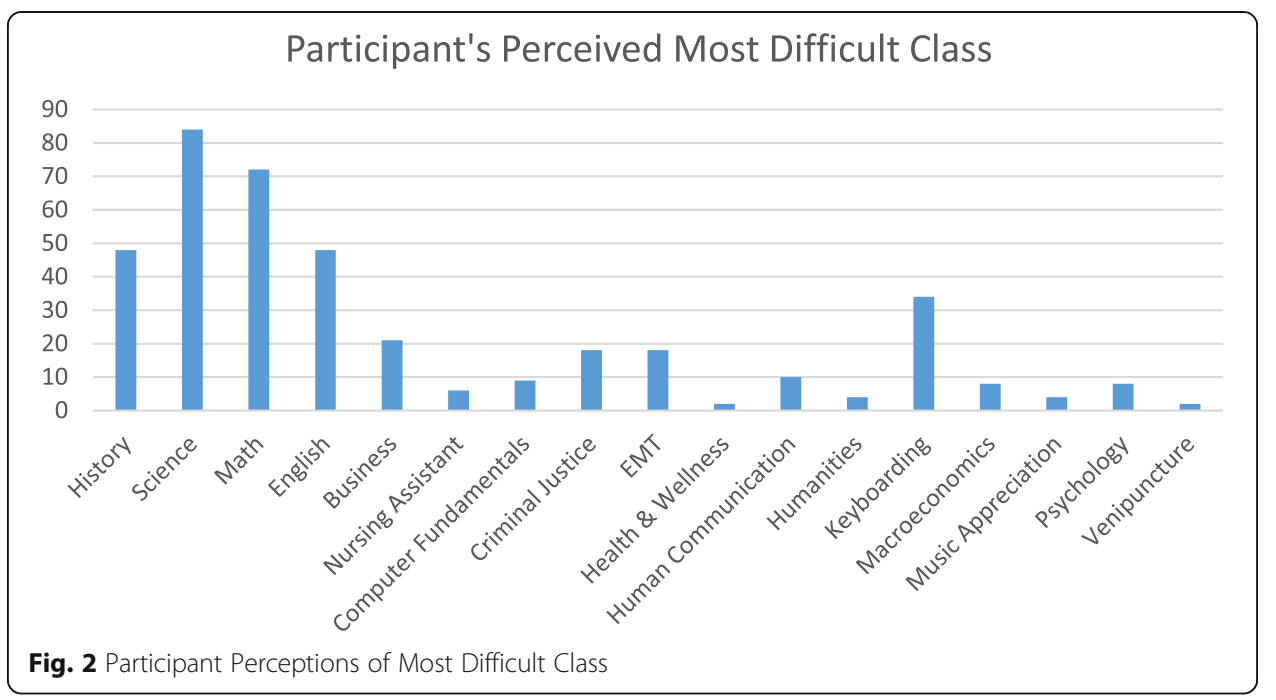

subscales while students who expected to earn final letter grade of a "C" scored the lowest. Consistent with Bandura's beliefs, students who had successful previous educational experiences believed they would receive an "A" or "B" in their first college class. Students who participated in the survey selected Science, Mathematics, English and History as the most difficult college classed.

\section{Instrument reliability analysis}

The reliability of the MSLQ was tested using Cronbach's alpha, to measure of the internal consistency of the instrument and to determine if all subscales will correlate with each other. Alpha coefficients ranged from 0.53 to 0.90 that signifies that there is good to strong reliability within the 81-question instrument. The MSLQ Manual listed confirmatory factor analyses results for each item, subscale and scale. The goodness of fit indices and Cronbach's Alpha coefficients were reasonable for each subscale given the fact that this survey was used across a broad assortment of courses and subject domains. The difference in reported manual scores and those in this study are likely due to course characteristics, teacher demands, and individual student characteristics. Generally, the model shows sound structures and can reasonably claim factor validity and reliability for the MSLQ scales (Table 2).

Research question two examined the relationship between independent variable (number of classes taken) and the dependent variable (MSLQ scores). The second research question determined there is a relationship between the number of college credits taken and the use of higher level skills and abilities by students. This question was analyzed using Pearson correlation coefficients to determine significant correlations for each pair of data. The significance level was set at alpha $p<.05$ level. The control of learning beliefs subscales was a negative weak correlation with the number of hours taken $[r=-.148, n=188, p=.043]$. The rehearsal subscale showed a weak positive correlation to the number of courses taken $[r=.218, n=184, p=.003]$. There was a weak positive correlation between the elaboration subscale and the number of courses taken $[r=.184, n=180, p=.013]$. The number of courses taken, and the metacognitive selfregulation subscale showed a positive weak correlation $[r=.226, n=178, p=.002]$. The 
Table 2 Means, SD, and internal consistency (Cronbach's Alpha) coefficients

\begin{tabular}{lllll}
\hline MSLQ subscale & Means & SD & $n$ & $a$ \\
\hline Intrinsic goal orientation & 4.63 & 1.24 & 193 & 0.762 \\
Extrinsic goal orientation & 5.73 & 1.12 & 192 & 0.704 \\
Task value & 4.90 & 1.37 & 181 & 0.863 \\
Control of learning beliefs & 5.08 & 1.08 & 186 & 0.619 \\
Self-efficacy for learning and performance & 5.38 & 1.19 & 188 & 0.619 \\
Test anxiety & 4.62 & 1.34 & 190 & 0.897 \\
Rehearsal & 4.33 & 1.33 & 183 & 0.738 \\
Elaboration & 4.39 & 1.24 & 177 & 0.689 \\
Organization & 4.29 & 1.52 & 184 & 0.804 \\
Critical thinking & 4.26 & 1.13 & 179 & 0.794 \\
Metacognitive self-regulation & 4.24 & 1.12 & 177 & 0.668 \\
Time and study environment & 4.65 & 0.92 & 167 & 0.827 \\
Effort regulation & 4.76 & 1.06 & 186 & 0.582 \\
Peer learning & 4.13 & 1.25 & 184 & 0.525 \\
Help seeking & 4.17 & 1.22 & 181 & 0.558 \\
\hline
\end{tabular}

Note. SD Standard Deviation, $n$ number of participants

effort regulation subscale and the number of courses taken showed a positive weak correlation $[r=.179, n=188, p=.014]$.

Additionally, scatterplots were used to show the correlation between the two variables and to determine how much one variable was affected by another. New DE participants showed significantly lower scores on the intrinsic goal orientation, self-efficacy for learning and performance, rehearsal, elaboration, organization, metacognitive selfregulation, and effort regulation subscales. Significant increases in intrinsic goal orientation and self-efficacy for learning and performance scores occurred after students completed 16 or more credit hours. Significant increases in rehearsal, organization and elaboration occurred after $29 \mathrm{~h}$ were completed, and increased scores in metacognitive self-regulation occurred after 15 credit hours were completed.

The third research question investigated the independent variable (teacher type) on the dependent variable (MSLQ scores) used. The third research question determined students taught by only college faculty or a combination of college faculty and high school teacher scored higher on MSLQ subscales than those taught only by high school teachers acting as adjunct college faculty. The ANOVA showed a significant effect of teacher type (college faculty, high school faculty, or both high school and college faculty) at the $p<.05$ level for the following dependent variables: Control of Learning Beliefs $[\mathrm{F}(2,187)=5.83, p=.003]$, Rehearsal $[\mathrm{F}(2,183)=4.19, p=.017]$, Organization [F $(2,185)=4.89, p=.009]$, Critical Thinking $[\mathrm{F}(2,180)=11.17, p=.000]$, Metacognitive Self-Regulation $[\mathrm{F}(2,177)=3.32, p=.038]$ and Peer Learning $[\mathrm{F}(2,185)=3.50, p=.032]$. An independent-samples t-test was conducted to compare the scores on the SelfEfficacy for Learning and Performance and the Metacognitive Self-regulation subscales in students taught by high school teachers and students taught by college faculty conditions. There was a significant difference in the scores for IV college faculty $(\mathrm{M}=4.38$, $\mathrm{SD}=1.11)$ for the DV Metacognitive Self-Regulation conditions $\mathrm{t}(154)=-2.285$, $p=.024$. There was a not a significant difference in the scores for high school teachers 
or college faculty for the DV Self-Efficacy for Learning and Performance. To analyze this data, independent $\mathrm{t}$-tests were used to compare the means of the two independent groups in order to determine whether there was statistical evidence that the associated population means were significantly different. According to school administrators, decisions about class location and instructor selection were often based on convenience rather than student need. This question determined students taught by college faculty scored higher on the self-efficacy and self-regulation portions of the MSLQ. The results of the Levene's test indicate that the variances of the two populations are assumed to be approximately equal. Thus, the standard $t$ test was used. This data was analyzed using independent t-tests to compare the means of each of the two independent groups to determine there was statistical evidence that the associated population means are significantly different. The results of an independent $\mathrm{t}$ test were not significant for the Self Efficacy subscale [F $(161)=1.103, p=.961$ ] but were significant for the Metacognitive Self-Regulation subscale [F $(156)=.532, p=.024, d=-0.413$ ] for those students taught by college faculty and those taught by high school teachers.

The fourth research question investigated the independent variable (class location) and the dependent variable (MSLQ scores). The fourth research question determined there is a significant difference in the reported MSLQ scores by students based on campus location. An analysis of variance (ANOVA) was used to analyze reported MSLQ scores based on the seven variations of class locations (high school campus only, college class only, online only, high school and college campus, high school campus and online, college campus and online, or high school, college campus, and online) to determine the statistical significance of the difference in the means of the various groups. There was a significant effect for the following subscales on the MSLQ: Task Value [F $(6,175)=3.78, p=.001, \eta 2 \mathrm{p}=.115]$, Control of Learning Beliefs $[\mathrm{F}(6,182)=3.12$, $p=.006, \eta 2 \mathrm{p}=.093]$, Test Anxiety [F $(6,184)=2.24, p=.041, \eta 2 \mathrm{p}=.068]$, Rehearsal $[\mathrm{F}$ $(6,178)=3.55, p=.002, \eta 2 \mathrm{p}=.107]$, Elaboration $[\mathrm{F}(6,173)=2.48, p=.025, \eta 2 \mathrm{p}=.079]$, Organization $[\mathrm{F}(6,180)=3.04, p=.007, \eta 2 \mathrm{p}=.092]$, Critical Thinking $[\mathrm{F}(6,175)=3.93$, $p=.001, \eta 2 \mathrm{p}=.118]$ indicating very strong evidence against H0. Students who participated in classes on college campus only scored highest on intrinsic goal orientation, task value, control of learning beliefs, organization, effort regulation and help seeking. Students who took classes at the online/college campus scored highest on extrinsic goal orientation, rehearsal, critical thinking, metacognitive self-regulation, and peer learning subscales. Students who took classes at the high school/college campus scored highest on self-efficacy for learning and performance and students who took classes online only scored highest for test anxiety. Students who took classes on the high school, college campus and online campuses scored consistently lower on all subscales except for help seeking (Table 3).

Tukey HSD tests showed significant differences in the task value subscale between students attending classes at the college campus location $(M=5.54, S D=1.23)$ and those taking classes online $(M=4.10, S D=1.50)$ or at the high school/college location $(M=5.44, S D=1.37)$ at the $p=.002$ level. Significant differences were also noted for the task value subscale between online students $(M=4.10, S D=1.50)$ and high school/ college $(M=5.44, S D=1.37)$ at the $p=.011$ level. The control of learning subscale showed significant differences in students attending classes at the college campus ( $M=$ $5.76, S D$.993) and those attending at high school/online $(M=4.61, S D=.865)$ at the 
Table 3 Means and SD for MSLQ by campus location

\begin{tabular}{|c|c|c|c|c|c|c|c|c|c|c|c|c|c|c|}
\hline \multirow[t]{2}{*}{ MSLQ subscale name } & \multicolumn{2}{|c|}{$\begin{array}{l}\text { High } \\
\text { school }\end{array}$} & \multicolumn{2}{|c|}{$\begin{array}{l}\text { College } \\
\text { campus }\end{array}$} & \multicolumn{2}{|c|}{$\begin{array}{l}\text { Online } \\
\text { campus }\end{array}$} & \multicolumn{2}{|c|}{$\begin{array}{l}\text { College \& } \\
\text { high school }\end{array}$} & \multicolumn{2}{|c|}{$\begin{array}{l}\text { High school } \\
\text { \& online }\end{array}$} & \multicolumn{2}{|c|}{$\begin{array}{l}\text { College } \\
\& \text { online }\end{array}$} & \multicolumn{2}{|c|}{$\begin{array}{l}\text { High school } \\
\text { college, and } \\
\text { online }\end{array}$} \\
\hline & M & SD & M & $S D$ & M & $S D$ & M & $S D$ & M & $S D$ & M & $S D$ & M & $S D$ \\
\hline $\begin{array}{l}\text { Intrinsic goal } \\
\text { orientation }\end{array}$ & 4.61 & 1.25 & 5.17 & 1.11 & 4.59 & 1.41 & 4.66 & 1.32 & 4.31 & 1.08 & 4.85 & 1.11 & 4.07 & 1.32 \\
\hline $\begin{array}{l}\text { Extrinsic goal } \\
\text { orientation }\end{array}$ & 5.67 & .999 & 5.76 & 1.46 & 5.70 & .984 & 5.83 & 1.29 & 5.84 & .783 & 5.84 & 1.06 & 5.33 & 1.20 \\
\hline Task value & 4.89 & 1.38 & 5.54 & 1.23 & 4.10 & 1.50 & 5.44 & 1.37 & 4.95 & 1.05 & 5.02 & 1.28 & 4.32 & 1.29 \\
\hline $\begin{array}{l}\text { Control of learning } \\
\text { beliefs }\end{array}$ & 5.00 & 1.18 & 5.76 & .993 & 5.00 & 1.00 & 5.09 & 1.05 & 4.61 & .866 & 5.15 & 1.00 & 4.80 & 1.19 \\
\hline $\begin{array}{l}\text { Self-Efficacy for learning } \\
\& \text { performance }\end{array}$ & 5.41 & 1.05 & 5.39 & 1.58 & 5.31 & .914 & 5.54 & 1.17 & 5.44 & .897 & 5.44 & 1.40 & 5.02 & 1.07 \\
\hline Test anxiety & 4.79 & 1.27 & 4.24 & 1.41 & 5.07 & 1.03 & 4.14 & 1.66 & 4.59 & 1.31 & 5.04 & 1.11 & 4.31 & 1.35 \\
\hline Rehearsal & 3.97 & 1.33 & 4.83 & 1.25 & 4.50 & 1.34 & 4.39 & 1.56 & 4.00 & 1.00 & 4.96 & 1.33 & 3.63 & .952 \\
\hline Elaboration & 4.29 & 1.19 & 4.56 & 1.32 & 4.83 & 1.31 & 4.58 & 1.21 & 4.03 & 1.10 & 4.79 & 1.31 & 3.69 & .898 \\
\hline Organization & 3.90 & 1.40 & 4.94 & 1.35 & 4.79 & 1.48 & 4.48 & 1.53 & 4.13 & 1.43 & 4.42 & 1.79 & 3.41 & 1.28 \\
\hline Critical thinking & 4.15 & 1.09 & 4.62 & 1.10 & 4.52 & 1.23 & 4.07 & 1.13 & 3.92 & .904 & 4.85 & 1.17 & 3.46 & 1.02 \\
\hline $\begin{array}{l}\text { Metacognitive self- } \\
\text { regulation }\end{array}$ & 4.14 & 1.19 & 4.38 & 1.21 & 4.38 & 1.21 & 4.44 & .996 & 4.29 & 1.18 & 4.00 & .887 & 4.57 & 1.23 \\
\hline $\begin{array}{l}\text { Time and study } \\
\text { environment }\end{array}$ & 4.80 & 1.06 & 4.71 & 1.03 & 4.42 & .646 & 4.66 & 1.14 & 4.56 & .652 & 4.73 & .932 & 4.55 & .594 \\
\hline Effort regulation & 4.64 & 1.03 & 5.04 & 1.18 & 5.01 & 1.04 & 4.91 & 1.12 & 4.53 & 1.03 & 4.70 & 1.08 & 4.45 & .805 \\
\hline Peer learning & 4.09 & 1.11 & 4.50 & 1.34 & 3.92 & 1.22 & 3.98 & 1.17 & 4.06 & 1.06 & 4.54 & 1.50 & 3.57 & 1.30 \\
\hline Help seeking & 4.31 & 1.15 & 4.43 & 1.32 & 4.16 & 1.33 & 4.26 & .889 & 3.71 & 1.27 & 4.01 & 1.29 & 4.19 & 1.18 \\
\hline
\end{tabular}

$p=.042$ level. The rehearsal subscale also showed significant differences between students attending at high school/college/online location $(M=3.63, S D=.952)$ both students who attended classes at the college campus/online $(M=4.96, S D=1.33)$ and students who attended classes at the high school/college location $(M=4.39, S D=1.56)$ at the $p=.008$ level.

\section{Discussion}

When used in conjunction, the research questions addressed (i) students' perceived skills, (ii) students' development of motivation and learning strategies throughout the program and (iii) teachers' impact on student development while focusing on critical skills for college readiness and successful transition to full college student. The overall findings indicate that motivation and learning strategy usage progress as students take college classes however, scores drastically increased once students completed three or more classes, indicating students with 9 or more credit hours exhibit the highest levels of motivation and learning strategy usage. College faculty, unfamiliar with teaching high school students, may struggle with how to engage students and what level of support to provide to them to ensure college success without compromising academic rigor but the findings of this study found college faculty who teach Dual Enrollment students to produce students who are more satisfied, more independent, and more responsible. Each campus type offers unique benefits to students yet students who participate at college campuses or any variation including a college campus scored higher on MSLQ subscales. This study corresponds with previous literature that found students 
participating in classes at college campuses had a more authentic college experience and found their classes to be of greater value (Burns \& Lewis, 2000).

This study is limited to selected high school students and home-schooled students who participated in the Dual Enrollment program in Southwest Georgia in the Fall of 2018. In order to participate in Georgia's Dual Enrollment program, students met minimum entrance scores on standardized tests, so these students cannot be directly compared to other high school students not meeting the admissions criteria. Because a randomized design was not used, preexisting characteristics may not be able to be controlled for. Data were limited to students who voluntarily elected to participate in the study, and were over the age of 18, or had signed parental consent. In an attempt to minimize threats to generalizability, the research documented detailed characteristics of the population sampled which could be used in the future to determine generalizability of the findings in another population. Data indicated positive overall outcomes (course completion and GPA) for the program; however, program critics, parents, teachers, school administrators, and other stakeholders still question the actual development of college readiness through the Dual Enrollment program. Therefore, determination of student perceptions of actual student practices during the transitional development phase were critical for overall program improvement. The institutions in this study successfully delivered Dual Enrollment courses to area high school students for more than 5 years, therefore the students' perceptions from each of the institutions could be influential in future program modifications.

One main assumption was that students truthfully and accurately reported their levels of motivation and use of learning strategies. Another assumption in which the research was pursued was that students were truthful and accurately reported their levels of motivation and use of learning strategies. All questionnaires were administered during class time or independently by the student online. This means that standardization of the questionnaire completion could be a limitation of the research.

Additionally, due to the type of questionnaire being administered to underage participants, research consent had to be obtained by the college president at each institution, superintendent of each county, parents, and finally students which further reduced the sample size and participant variability. As a convenience sample, this study included participants who were purposefully selected, at particular sites, target institutions, and four surrounding high schools. The study size was limited by the overall sample size of 213, that were enrolled at a state college and a technical college. During survey collection, a natural disaster occurred causing schools to be closed, there was an extended loss of power, therefore the weather affected the population and sample size. Some participants did not complete all questions on the survey. To account for the missing list wise deletion method was used and the missing data was excluded.

This study was primarily designed to provide motivational and learning strategy information of high school students who are participating in college classes to program stake holders, including teachers and school administrators. This information provided noteworthy implications for policy makers regarding the effects of course planning with respect for total qualification of the instructor, where the class is taught at, and expectations for the progression of motivation and learning strategies as students advance though the DE program. This study was primarily designed to provide practical implications for Dual Enrollment students, college faculty, high school teachers serving as 
adjunct faculty, school administrators, Dual Enrollment coordinators and guidance counselors with insight into the motivational orientations and learning strategy usage of Dual Enrollment students.

The findings from this study are consistent with current theories in the field added to the knowledge that Dual Enrollment are distinctive learners and need additional support with the nonacademic facets of transitioning into the college student role. Given more assistance and better planning by faculty, students can better understand faculty's expectations, think more critically, and regulate their behaviors. Each student is a unique learner and possesses their own set of motivations, goals, and career aspirations so each learner's frame of reference, college readiness, and academic skill level all develop at different paces but in order to navigate a complex college system, they must adapt quickly to new norms and expectations based off of prior experiences.

The social cognitive theory provided context for the study but the concentration on student's cognitive, metacognitive, and resource management development while participating in the Dual Enrollment program revealed vital information to school administrators, college administration, college faculty, high school teachers, parents, and students with a better understanding of how Dual Enrollment classes prepare students for the traditional college experience after high school graduation, how to better meet the needs of this specific type of learner, and offers them insight into the actual perceptions and expectations of current participating students.

At the local level, the results have helped to ease students into college classes, complete college faster, and reduce student loan debt. The Dual Enrollment program offers a mutually beneficial relationship to high schools by allowing varied classes be taught to their students for free and Georgia colleges by increasing enrollment numbers. Courses taught at the college offer the students variation in the curriculum offered at the high school campus, which will give the student a more accurate idea of academic area of interest. By exposing students to college coursework and integrating students with traditional college students, the transition to college is smoother because they have models to imitate. Rapid expansion of the Dual Enrollment program has brought about concern of participants' college readiness. Though many previous studies established the benefits of Dual Enrollment outcomes, none addressed the motivational orientations and learning strategy usage by students. By assessing this information, program officials, school administrators, teachers, and parents can better meet the needs of these students while making the Dual Enrollment program operate more efficiently.

Acknowledgments

We are grateful for the support we received from Valdosta State University; we would like to thank all the students and teachers who participated in this research.

\section{Authors' contributions}

MCD drafted the initial manuscript and reviewed the literature. HMK revised and reviewed the manuscript. MCD performed data analysis and BB provided supervision of the research. HMK, BB, and SJK provided insight and editing of the manuscript. All authors read and approved the final manuscript.

Funding

Not applicable.

Availability of data and materials

The datasets used and/or analyzed during the current study are available from the corresponding author on reasonable request. 
Ethics approval and consent to participate

The Valdosta State University Research Ethics Board reviewed the research and approved on ethical grounds on September 25, 2018.

\section{Competing interests}

The authors declare that they have no competing interests.

\section{Author details}

'Department of Psychology, Counseling, and Family Therapy, Valdosta State University, 1802 Lake Circle Dr. Bainbridge, Valdosta, GA 39819, USA. ${ }^{2}$ Valdosta State University, Valdosta, GA, USA.

Received: 25 July 2019 Accepted: 24 August 2020

Published online: 09 September 2020

\section{References}

Ali, L., Hatala, M., Gašević, D., \& Winne, P. (2014). Leveraging MSLQ data for predicting students achievement goal orientations. Journal of Learning Analytics, 1(3), 157-160. https://doi.org/10.18608/jla.2014.13.11.

Bandura, A. (1986). Social foundations of thought and action: a social cognitive theory. Englewood Cliffs: Prentice-Hall.

Bandura, A. (1997). Self-efficacy: the exercise of control. New York: Freeman.

Bandura, A. (1999). Self-efficacy: toward a unifying theory of behavioral change. In R. F. Baumeister (Ed.), The self in social psychology. Key readings in social psychology, (pp. 285-298). Philadelphia: Psychology Press/Taylor \& Francis.

Burns, H., \& Lewis, B. (2000). Dual-enrolled students' perception of the effect of classroom environment on educational experience. The Qualitative Report, 4(1), 1-10 Retrieved from https://nsuworks.nova.edu/tar/vol4/iss1/7.

Community College Research Center (2017). What happens to students who take community college "dual enrollment" courses in high school? (pp. 1-32). New York: National Student Clearinghouse Research Center Retrieved from https://ccrc.tc. columbia.edu/media/k2/attachments/what-happens-communitycollege-dual-enrollment-students.pdf.

Conley, D. T. (2006). What we must do to create a system that prepares students for college success. San Francisco: WestEd.

Crede, M., \& Phillips, L. A. (2011). A meta-analytic review of the motivated strategies for learning questionnaire. Learning and Individual Differences, 21, 337-346. https://doi.org/10.1016/j.lindif.2011.03.002.

Deruy, E. (2015). Why high schools are pushing the weakest students to enroll in college courses. The Atlantic Available at: https://www.theatlantic.com/education/archive/2015/07/college-classes-for-highschool-students/398522/ [Accessed 27 Mar. 2018].

Duncan, T., \& McKeachie, W. (2005). The making of the motivated strategies for learning questionnaire. Educational Psychologist, 40(2), 117-128. https://doi.org/10.1207/s15326985ep4002_6.

Eccles, J. S. (2005). Subjective task values and the Eccles et al. model of achievement related choices. In A. J. Elliot, \& C. S. Dweck (Eds.), Handbook of competence and motivation, (pp. 105-121). New York: Guilford.

Erickson, A. and Noonan, P. (2013). College \& career competency framework: self regulation. [online] Researchcollaboration. org. Available at: http://www.researchcollaboration.org/uploads/TeacherGuide-Self-Regulation.pdf [Accessed 17 Apr 2018]

Governor's Office of Student Achievement (2017). Georgia Dual Enrollment and postsecondary outcomes. Atlanta, GA: The Governor's Office of Student Achievement, pp. 1-23.

Hughes, K. (2010). Dual enrollment: postsecondary/secondary partnerships to prepare students. Retrieved from https://ccrc.tc. columbia.edu/publications/dual-enrollment-postsecondary-secondary.html

Hughes, K., \& Edwards, L. (2012). Teaching and learning in the dual enrollment classroom. New Directions for Higher Education, $158,29-37$.

Jenkins, R. (2017). Let's not throw the dual enrollment baby out with the bathwater, (pp. 1-4). Raleigh: The James G. Martin Center for Academic Renewal.

Kanny, M. (2015). Dual enrollment participation from the student perspective. New Directions for Community Colleges, 169, 5970.

Karp, M. (2007). Learning about the role of college student through dual enrollment participation. New York: Community College Research Center, Columbia University Teachers College.

Karp, M. (2012). "I don't know, I've never been to college!" dual enrollment as a college readiness strategy. New Directions for Higher Education, 158, 21-28. https://doi.org/10.1002/he.20011.

Kaur, H., \& Kaur, K. (2014). A study of adolescent's strengths and difficulties and academic self-regulation. Indian Journal of Health \& Wellbeing, 5(8), 913-917.

Khan, M. (2013). Academic self-efficacy, coping, and academic performance in college. International Journal of Undergraduate Research and Creative Activities, 5(1), 1-11. https://doi.org/10.7710/2168-0620.1006.

Kitsantas, A., Winsler, A., \& Huie, F. (2008). Self-regulation and ability predictors of academic success during college: A predictive validity study. Journal of Advanced Academics, 20(1), 42-68. https://doi.org/10.4219/jaa-2008-867.

Kivinen, K. (2003). Assessing motivation and the use of learning strategies by secondary school students in three international schools. Ph.D. University of Tampere.

Magno, C. (2011). Validating the academic self-regulated learning scale with the motivated strategies for learning questionnaire (MSLQ) and learning and study strategies inventory (LASSI). The International Journal of Educational And Psychological Assessments, 7(2), 56-73.

McGrew, K. (2008). Academic self-efficacy. St. Joseph: Institute for Applied Psychometrics Retrieved from http://www.iaspsych. com/acmcewok/Academicself-efficacy.html.

Morrow, J., \& Torrez, A. (2012). On track to their dreams. Educational Leadership, April, 74-77.

National Research Council (2002). Learning and understanding: Improving advanced study of mathematics and science in U.S. high schools. Washington, DC: National Academy Press.

Pajares F., (2002). Overview of social cognitive theory and of self-efficacy. Retrieved 1 Apr 2018, from http://www.emory.edu/ EDUCATION/mfp/eff.html 
Pintrich, P. R. (1989). The dynamic interplay of student motivation and cognition in the college classroom. In C. Ames, \& M. L. Maehr (Eds.), Advances in motivation and achievement: motivation-enhancing environments, (vol. 6, pp. 117-160).

Pintrich, P. R., Smith, D., Duncan, T., \& McKeachie, W. (1991). A manual for the use of the Motivated Strategies for Learning Questionnaire (MSLQ), (vol. 48109, p. 1259). Ann Arbor: National Center for Research to Improve Postsecondary Teaching and Learning.

Puustinen, M., \& Pulkkinen, L. (2001). Models of self-regulated learning: a review. Scandinavian Journal of Educational Research, 45(3), 269-286.

Rauschenberg, S. \& Chalasani, K. (2017). A Longitudinal Analysis of Dual Enrollment Outcomes from 2008 to 2016. Georgia Dual Enrollment and Postsecondary Outcomes, 1-19. Retrieved from: https://gosa.georgia.gov/sites/gosa.georgia.gov/files/ Dual\%20Enrollment\%20and\%20Postsecondary\%200utcomes\%20Report\%20from\%202008\%20to\%202016\%20Nov9201 7\%20FINAL.pdf [Accessed 3 Apr. 2018].

Schunk, D., \& Zimmerman, B. (1994). Self-regulation of learning and performance: issues and educational application. Hillsdale: Lawrence Erlbaum Associates, Inc.

Senko, C. (2016). Achievement goal theory: a story of early promises, eventual discords, and future possibilities. In K. Wentzel, \& D. Miele (Eds.), Handbook of motivation, (2nd ed., pp. 75-95). New York: Routledge.

Tobolowsky, B., \& Allen, T. (2016). On the fast track: understanding the opportunities and challenges of dual credit. ASHE Higher Education Report, 42(3), 7-106.

Wigfield, A. (1994). Expectancy-value theory of achievement motivation: a developmental perspective. Educational Psychology Review, 6(1), 49-78. https://doi.org/10.1007/bf02209024.

Wolters, C. A. (1998). Self-regulated learning and college students' regulation of motivation. Journal of Education \& Psychology, 90(2), 224-235. https://doi.org/10.1037/0022-0663.90.2.224.

Zimmerman, B. (1986). Becoming a self-regulated learner: which are the key subprocesses? Contemporary Educational Psychology, 11(4), 307-313. https://doi.org/10.1016/0361-476x(86)90027-5.

Zimmerman, B. (1989). A social cognitive view of self-regulated academic learning. Journal of Education \& Psychology, 81(3), 329-339.

Zimmerman, B. (2000). Self-efficacy: an essential motive to learn. Contemporary Educational Psychology, 25(1), 82-91. https:// doi.org/10.1006/ceps.1999.1016.

Zimmerman, B. (2002). Becoming a self-regulated learner: an overview. Theory Into Practice, 41(2), 64-70.

Zumbrunn, S., Tadlock, J., \& Roberts, E. (2011). Encouraging self-regulated learning in the clasroom: A review of the literature (pp. 3-20). Virginia: Metropolitan Educational Research Consortium.

\section{Publisher's Note}

Springer Nature remains neutral with regard to jurisdictional claims in published maps and institutional affiliations.

\section{Submit your manuscript to a SpringerOpen ${ }^{\circ}$ journal and benefit from:}

- Convenient online submission

- Rigorous peer review

- Open access: articles freely available online

High visibility within the field

- Retaining the copyright to your article

Submit your next manuscript at $\boldsymbol{\nabla}$ springeropen.com 